is more complex than that. In search of making sense of symptoms by the health professionals, we believe that the first step is by understanding the symptoms and the distress experienced by the individuals themselves through their identification that something has gone wrong; then their search for a possible explanation for their distress will lead to identifying possible sources of help and then finding a way to seek relief. However, in this process of help-seeking there are numerous culturally determined barriers. Stigma will indeed be a potential barrier but it is also likely that other factors may help modify the idioms of distress. In an earlier study of middleaged Punjabi women, we found that they were able to identify symptoms of depression, and life events causing it, but they also felt that these symptoms were part of life's ups and downs and not a medical condition; hence, they preferred to seek solace in religious places (Bhugra et al, 1997). They identified both psychic and somatic symptoms but were also clear in their discussion that sources of help were not medical. Similar observations were made in Dubai (Sulaiman et al, 2001). Our conjecture is that globalisation will influence the way individuals see their distress because media influences may affect their cognitive schema. Cognitive schema determine the meanings we impart to ongoing experience and give an expectation of the future (Strauss \& Quinn, 1997). We do not hold the view that somatisation is enigmatic. It is a perfectly understandable representation of the distress which is a reflection of the explanatory models held by the individual.

Bhugra, D., Baldwin, D. \& Desai, M. (1997) Focus groups: implications for primary and cross-cultural psychiatry. Primary Care Psychiatry, 3, 45-50.

Strauss, C. \& Quinn, N. (1997) A Cognitive Theory of Cultural Meaning. Cambridge: Cambridge University Press.

Sulaiman, S., Bhugra, D. \& De Silva, P. (200I) Perceptions of depression in a community sample in Dubai. Transcultural Psychiatry, 38, 201-218.

D. Bhugra Section of Cultural Psychiatry, Institute of Psychiatry, PO25, De Crespigny Park, Denmark Hill, London SE5 8AF, UK

\section{Disability and post-traumatic stress}

Neal et al (2004) recently found no association between post-traumatic stress and judgement of disability. Therefore, they concluded that the clinical importance of post-traumatic stress disorder (PTSD) and its symptoms may be questionable. However, in our opinion their conclusions need additional consideration.

First, their multivariate analysis of variance compared the degree of disability of persons with PTSD with that of people with other mental health problems. From their results they could only conclude that PTSD caused no additional disability compared with other mental health problems. Moreover, from a statistical point of view, the sample size is not sufficiently large, especially when one tries to find differences between groups given the significance level used $(P=0.01)$. In addition, the authors do not give insight in the multicollinearity between the independent variables of the multiple regression analysis; the expected high intercorrelations may have influenced the results.

Second, is it not strange to question disability in people with PTSD, major depressive disorder or alcohol dependence, while disability in social or professional functioning or in other important areas is a requirement for all DSM-IV diagnoses? Also, the authors took subjective judgement of disability as their main outcome measure and not objective measures of disability, such as the number of days not at work.

Third, previous studies found contrasting results. Brown et al (1996) and Lydiard (1991) report that major depressive disorder comorbid with anxiety disorders (i.e. PTSD) is more severe than major depressive disorder alone in terms of depressive symptoms, course of illness and treatment response. Finally, even if PTSD does not cause additional disability above major depression, the diagnosis is still relevant for the correct choice of treatment.

Brown, C., Schulberg, M. J., Madonia, M. J., et al (1996) Treatment outcomes for primary care patients with major depression and lifetime anxiety disorders. American Journal of Psychiatry, 153, 1293-1300.

Lydiard, B. (1991) Coexisting depression and anxiety: special diagnostic and treatment issues. Journal of Clinical Psychiatry, 52, 48-52.

Neal, L. A., Green, G. \& Turner, M. A. (2004) Posttraumatic stress and disability. British Journal of Psychiatry, 184, 247-250.

J. Roorda Regional Health Authority Twente Enschede Firework Disaster Health Monitoring Project, Postbus 1400, 7500 BK Enschede, The Netherlands

M. L. Meewisse, G.-J. de Vries Specialty Programme for Psychotrauma, Academic Medical Centre of the University of Amsterdam,

The Netherlands
A. J. E. Dirkzwager Netherlands Institute for Health Services Research (NIVEL), Utrecht, The Netherlands

Author's reply: The multivariate analysis of variance demonstrated no significant difference between the group with DSM-IV PTSD and the group without DSM-IV PTSD in terms of the severity of disability. This finding is unrelated to the other mental health problems measured in the study, as shown by the analysis of covariance. The power of the study was 0.85 (assuming a detectable difference of 3 out of 30 on the Sheehan Disability Scale and $\alpha=0.01)$. This is acceptable for limiting the chances of type II error. Multicollinearity is only of importance when trying to draw inferences about the relative contribution of more than one predictor variable to the success of the model. In this study the Beck Depression Inventory (BDI) (or its variant the M$\mathrm{BDI})$ was the only variable retained in the regression models and so multicollinearity is not an issue. Disability is not an absolute requirement in DSM-IV. The utility of objective measures of disability $v$. subjective measures was discussed in the paper. However, the subjective experience of the patient is probably of most value in clinical terms. Other studies have found contrasting results, as discussed in the paper's introduction. However, most have methodological limitations. The treatment of PTSD, as opposed to depression, may be relevant to the DSM-IV diagnostic criteria but may not be relevant to the patient.

L. A. Neal King's College London, and Bristol Priory Hospital, Heath House Lane, Stapleton, Bristol BSI6 IEQ, UK

\section{In defence of complainants}

It is interesting that the complaints involved within the study by Lester et al (2004) were not subject to independent legal scrutiny. The reader therefore has no idea of their merits.

Anyone who has experienced the difficulties of authorities and courts will realise that bureaucracy and confusion pervade each institution. Anyone who has attended one of our supreme courts will know that the service is slow, correspondence often goes missing, checks are required to ensure that the correct folders and paperwork are presented, and often uncomfortable questions are ignored. These are characteristics 
of the average day of a normal and rational human being attempting to protect his or her civil liberties. These are practical problems faced by the average person.

With the advent of the Human Rights Act 1998 civil liberties have come to the forefront. It is an Act that cannot be ignored. Indeed, with increasing litigation, authorities have by nature become defensive. Part of the method of making life impossible for complainants is to increase the bureaucracy.

The number of letters, phone calls, etc. reported by Lester et al (2004) may be part of 'normal' human behaviour and reaction to bureaucracy. In a democratic country, we all have a right to protect our civil liberties. Often litigants lack knowledge, have no idea of procedures, and are misled by authorities who have a vested interest in protecting themselves. To label this behaviour as an 'abnormality' or something that requires psychiatric intervention is ludicrous. Indeed, I note the Royal College of Psychiatrists runs a very successful antistigma campaign to stamp out discrimination against those with mental illness. The diagnosis of querulous paranoia runs the risk of misuse by those who wish to use psychiatry as a manner of silencing criticism. The behaviour exhibited in the study is indeed a normal reaction to the circumstances faced. 'Normal' of course depends on many variables such as response time of the complaint officers, failure to address questions, replies to phone calls, etc. These factors have not been addressed.

It stands to reason that psychiatrists are not judges. Indeed, the merits of the complaint will be subjectively assessed by each psychiatrist based on his or her prejudices. This is hardly independent.

Querulous paranoia is a diagnosis best left within the darkened past of psychiatry-perhaps pre-war Russia where Stalin often used 'madness' to silence his critics. Genetically, we are all 'different' by nature and react in various ways to injustices. It is essential to maintain the civil right to seek a remedy without interference from psychiatry. Interference from psychiatry will only increase the stigma associated with it for so many years.

It is often the case that different personas, atypical to the perceived norm, are subjected to psychiatric analysis. There is a minority of serial complainants but the difference is to ascertain whether their complaints have merits or not. A psychiatrist cannot assess this fairly. Without an independent legal assessment, any person who attempts to fight or campaign for their civil liberties runs the risk of being labelled with a psychiatric illness. Their credibility will often be substantially affected. This, indeed, may be a rather convenient way of silencing uncomfortable critics of negligent authorities. This was not what psychiatry was meant for and neither should it risk going down that route, given the good work done by the College's anti-stigma campaign on raising awareness of discrimination in mental health.

Lester, G., Wilson, B., Griffin, L., et al (2004) Unusually persistent complainants. British Journal of Psychiatry, 184, 352-356.

R. Pal PO Box 8553, Sutton Coldfield, West Midlands B76 2BS, UK

Author's reply: Judging from Dr Pal's letter we failed totally to communicate adequately the purpose, the methodology or the conclusions of our paper on unusually persistent complainants. Dr Pal's letter comes, therefore, as a welcome opportunity to clarify our views.

We scrupulously avoided the term querulous paranoia. The unusually persistent complainants and their controls were selected by professionals working within the ombudsmen's offices, many of whom are legally trained. We are studying not courts and bureaucracies, but organisations whose mission is to assist complainants find a satisfactory resolution to their grievances. The organisational responses to the complaint, far from being ignored, were examined as the most likely precipitant of unusual persistence.

Dr Pal's passionate defence of civil liberties and attack on 'misleading' bureaucracies set on 'silencing criticism' seems misplaced as a criticism of a paper aimed at understanding and assisting those currently damaged by engagement within systems of complaints resolutions. Dr Pal clearly has a generous view of 'normal reactions', which incorporates behaviours involving a total fixation on a grievance to the point where individuals consume all their time, resources and energies in a futile pursuit that lays waste their own, and their families', lives. Dr Pal also presumably encompasses within the notion of normal overt and covert threats against complaints officers and their families.
Having our approach compared to Stalin, even a Stalin who Dr Pal seems to believe improved his behaviour post-war, might be considered intemperate, directed as it is at the authors of a paper which attempted to broaden the sympathies and concerns of mental health professionals for a distressed and disturbed group within our communities.

P. Mullen Victorian Institute of Forensic Mental Health, Thomas Embling Hospital, Yarra Bend Road, Fairfield, Victoria 3078, Australia

\section{GHB and date rape}

I read with interest the important editorial by Rodgers et al (2004) on $\gamma$-hydroxybutyrate (GHB, liquid ecstasy) and the new threat it poses to young adults. It is worth adding the growing threat of the use of GHB as a 'date/acquaintance rape' drug; GHB is cited in this regard along with psychoactive substances such as flunitrazepam and ketamine (Smith, 1999).

GHB is a typical 'date rape' agent (O'Connell et al, 2000) as it is relatively easy to obtain, and it causes a rapid relaxing and disinhibitory effect. Moreover, since it is colourless and odour-free, it is easily added to the potential victim's drink without arousing any suspicion. These characteristics make it easy and less risky to perpetrate the crime. Additionally, GHB frequently causes the victim to be regarded as unreliable in the eyes of lawenforcement authorities because of changes in consciousness, perception, and anterograde amnesia, and at times hallucinations during and following the act.

Since GHB is difficult to identify in the urine as it is quickly eliminated from the body, it is rarely collected as evidence of the crime. This drug is not routinely checked for in urine toxicology screening kits and is therefore likely to be missed at the emergency room. Doctors and other professionals working with sexual assault victims should be aware of the possibility of GHB intoxication, more often than not, of an unknowing victim.

O’Connell, T., Kaye, I. \& Plosay, J. J. (2000) Gammahydroxybutyrate (GHB): a newer drug of abuse. American Family Physician, 62, 2478-82, 2483.

Rodgers, J., Ashton, C. H., Gilvarry, E., et al (2004) Liquid ecstasy: a new kid on the dance floor. British Journal of Psychiatry, 184, 104-106. 